\title{
The Research on Practice and Strategies of Teaching Supervision in Application-oriented Universities
}

\author{
Huifen Lai*, Yufan Diao, Yuhua Wang, Jinwei Zhou
}

Jiliang University College of Modern and Technology, Hangzhou, China

${ }^{*}$ Corresponding author. Email: huifenlai@163.com

\begin{abstract}
Based on the collection of policy documents and case studies of teaching supervision in application-oriented universities, this paper aims to understand the current situation of teaching supervision in Application-oriented Universities at home and abroad. Combined with the professional construction needs of modern science and Technology College of China Jiliang University, it extensively solicits the opinions of relevant functional departments, forms a teaching supervision system based on improving the quality of undergraduate teaching, and strengthens the functions and functions of supervision This paper makes a beneficial exploration and practice in strengthening and improving the teaching supervision, broadening and deepening the supervision function, improving the scientificity of supervision evaluation, and enhancing the effectiveness of supervision work.
\end{abstract}

Keywords: Teaching, Supervise, Practice, Application-oriented universities.

\section{应用型本科院校教学督导工作实践与策略探究}

\author{
赖惠芬*，フ宇凡，王玉华，周静伟
}

中国计量大学现代科技学院，杭州，中国

*通讯作者. 邮箱: huifenlai@163.com

中文摘要

本文通过对应用型本科院校教学督导工作政策文件搜集梳理和案例研究, 了解国内外应用型高校本科教学督导 的现状, 结合中国计量大学现代科技学院专业建设需要, 广泛征求相关职能部门的意见, 形成基于提高本科教 学质量的教学督导制度, 在强化督导的职能与作用, 加强和改进教学督导工作, 拓宽和深化督导功能, 提高督 导评价的科学性，提升督导工作的实效性方面进行了有益的探索和实践。

关键词: 教学, 督导, 实践, 应用本科

\section{1. 前言}

教学质量是学校声誉的载体, 是高校生存与发展 的生命线, 提高教学质量已成为当前教育改革发展的 核心任务。建立一套科学高效的内部教学质量保障体 系, 是高校不断提高教学质量的根本保证。对于应用 型本科院校而言, 教学是学校工作的中心, 保证并提 升教学质量的实现是教学督导的工作重点和使命。深
入探讨督导工作的实践是督导员非常重要的任务, 对 于更好地完善督导组织体系、督导工作内容、督导成 果评价等具有重要的意义。本项目的开展正是顺应了 目前教育部力推“金课”, 打造新时代一流本科教育的 要求, 使得教学督导工作在上层建设、细节设计、结 果评价等方面都取得进一步的改进, 打造督导质量监 控和保障体系闭环, 最终提高教学质量。 
教学督导工作就是依据一定的评价标准, 对学校 内部教学活动各个层面与各个环节进行全面检查、常 态监督、客观评估的过程。教学督导的根本点是促进 教育教学质量的提高, 促进本科院校实现培养高端技 能型人才目标。“督”与“导”是一个不可分割的整体, 前提是“督”, 重点是“导”。一般而言, 教学督导内容 主要有: 一是教学管理工作督导; 二是教学活动督导; 三是教师教学质量督导; 四是学生学习质量督导。前 两个方面强调的是过程, 后两个方面强调的是结果。

\section{2. 现状分析}

教学督导是高等学校深化教育管理体制改革, 构 建高校教学质量监控体系, 巩固和推动学校内涵发展, 提高教学质量和管理水平的重要组成部分。但目前我 国的教学督导制度尚处于发展阶段, 实践不充分, 理 论体系也不完善。具体而言, 主要表现为督导管理制 度缺失、督导队伍专业化程度不高、督导工作内容表 浅化、督导工作方式简单化, 以及高校对教学督导的 实质性支持难以保证等问题。这些问题的存在, 一方 面制约了高校教学督导工作的质量与水平, 另一方面 也为高校教学督导工作如何促进人才培养质量不断 提高留下了探索与实践的空间。

目前, 高校教学督导工作, 有的师资充足的高校 依靠本校退休教师、专家; 有的依靠外聘教师、专家; 有的由职能部门代管。每种模式各有千秋利弊, 只有 适合本校人才培养模式的教学督导模式才是最好的。 随着部分高校逐渐转型为应用技术型高校, 根据学校 的转型发展及应用型本科教育的教学实际需要, 教学 督导模式的创新方式已提上日程, “外”聘机制越来越 难发挥“督”、“导”的作用, 且随着应用型人才培养模 式的建立, 难免会出现 “督”与“导”的理念冲突。由职 能部门代管对教学质量的监控作用会大打折扣。

目前各大高校都非常重视教学督导工作, 学者们 纷纷对督导制度及其建设等等问题进行了相关的研 究。众学者对督导工作的研究视角各有不同, 为本项 目的开展奠定了扎实的理论基础。

中国计量大学现代科技学院各级领导高度重视督 导队伍的建设, 以科学发展理念为指导, 以督导职能 定位、内涵发展为重点, 以督导制度的构建为保障, 在加强和改进教学督导工作, 拓宽和深化督导功能, 提升督导工作的实效性方面进行了有益的探索和实 践。

\section{3. 项目实施方案}

应用型本科院校在人才培养和内部机构设置等方 面既不同于职业技术学校, 又有别于研究型本科院校。 因此, 在构建应用型本科院校教学督导运行机制时, 要转变传统的教育思想和人才培养观, 坚持创新思维, 立足应用型本科院校发展需要, 建立应用型本科院校 教学督导机制, 注重“目标导向”和“全覆盖”相结合。 将学校面临的各项评估指标分解细化, 制定教学督导
质量评价指标体系, 覆盖教学全过程, 使教学督导方 向更加明确、更加贴合学院发展需要, 以实现过程化、 标准化督导。

多次召开课题组筹备会议, 进行课题分工, 明确 具体任务。检索相关文献资料, 进行梳理和综述, 充 实理论研究, 为本研究建立文献基础, 并完成学理基 础的相关研究工作。通过政策文件搜集、深度梳理、 案例研究等形式, 摸清国内外应用型高校本科教学督 导的现状, 在此基础上完成案例研究工作。在文献研 究和案例研究的基础上, 结合中国计量大学现代科技 学院专业建设需要, 广泛征求相关职能部门的意见, 形成基于提高本科教学质量的教学督导制度, 从学院、 系部和专业建设三个层面制定规章制度, 在本科生培 养各个环节逐步形成制度并推进。在推进中不断进行 实施效果反馈机制研究, 并依据反馈结果及时调整规 章制度和实施方案。

实施方案流程框图如下:

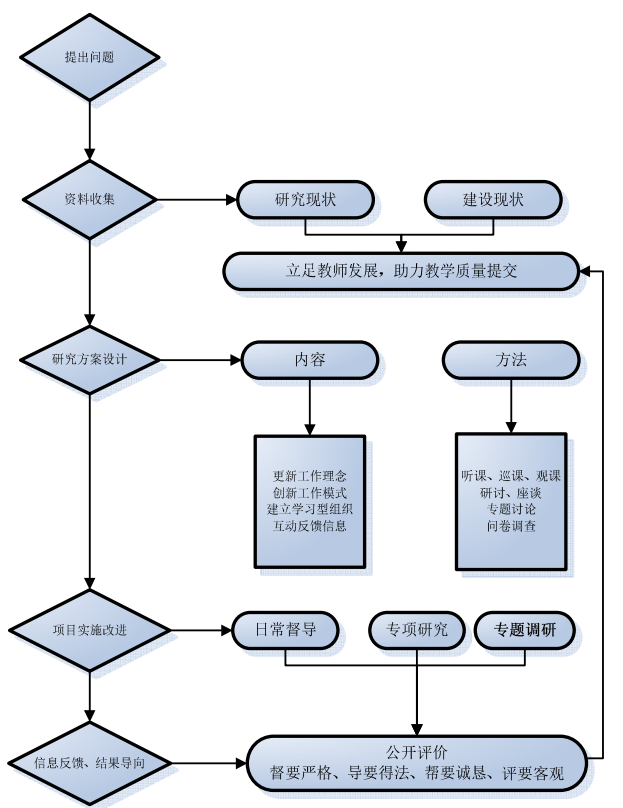

图 1 实施方案流程框图

\section{4. 改革内容}

\section{1. 明晰督导工作指导思想和定位, 优化督导 队伍的结构和专业性}

根据我院的专业特点，建议增加相关专业的督导 组成员，同时增加督导组成员的培训机会，尤其是对 国家教育方针政策的学习、教学理念和方法手段的学 习等, 深入学习各高校间好的督导工作经验, 多开展 教学督导组成员之间的沟通和相互学习, 提高督导组 成员的整体素质水平。助力教师教育与发展, 提高教 学质量, 适应人才培养需求, 服务于人才培养全过 程。 


\section{2. 拓展督导工作的发展性、多样性、开放性, 创新督导工作模式}

进一步深化以“督”为手段, 以“导”为目标的督导新 模式。建立督导工作的科学机制, 实现对各个教学环 节的质量监控, 另一方面充分调动教师的教学积极性, 在听课、检查后更多的给予教师正面的引导, 提出有 建设性的建议, 积极和教师沟通, 帮助教师解决教学 中的疑惑和亟待解决的问题, 建立良好的督导组成员 和教师的关系。

\section{3. 加强督导职能的评估、监测、指导作用, 深化督导评价制度建立，提高督导实践成果的 理论深度, 同时将理论成果更好的转化为督导 实践，缩短周期，提高督导水平}

进一步完善评价工作方案, 精简指标体系, 规范 评价程序, 突出评价重点, 及时总结经验, 建立评估 结果公开和通报制度, 对质量问题突出的课程进行重 点督导, 强化抽检结果使用, 对任课教师的评教要及 时地和任课教师沟通, 指出问题并提出中肯的改进意 见和建议, 让教师及时地发现不足, 有更多的提升空 间。

\section{4. 强化应用型高校各实践环节专项督导}

进一步开展实践教学环节诸如课内教学实验、专 设课程实验、生产实习、毕业实习、专业实习、课程 设计、学士学位毕业论文等专项检查, 对影响应用型 本科教学质量和人才培养质量的关键环节进行专题 研讨, 通过专项检查及时发现实践环节存在的问题, 能有效地督促学院不断加以改正。

\section{5. 解决的关键问题}

\section{1. 深入制度化建设和理论研究}

随着时代的发展, 高等教育出现了许多新的变化, 学校教学工作也出现了一些新情况和新问题, 这就要 求督导组成员具有与时俱进的思想。一方面根据国家 高等教育政策规定和学校教学管理文件要求在各项 教学检查中严格执行检查与监督; 另一方面不断加强 学习, 深入教学一线, 广泛接触师生, 发现各专业的 创新做法与成功经验, 为学院的教学管理提供有益的 建议。

\section{2. 健全教学督导信息反馈机制}

抓规范性是课堂教学质量监控的突破口, 课堂教 学质量监控是督导工作的重重之重, 以课堂教学质量 监控作为教学督导的重点工作, 以抓好课堂教学的规 范性作为提高课堂教学质量的突破口, 教学督导的形 式手段主要有巡查、听课评课、查阅资料。定期和随 机到教学现场进行教学督导巡查, 主要目的是维护正
常的教学秩序, 促使教师学生准时上下课, 确保教师 不随意调、停课, 学生不随意在上课时间去做义工等 与上课无关的工作。

\section{3. 有效开展青年教师培训与考核}

从 2018 年开始, 借校园迁建之机, 学院招聘大量 青年教师, 如何引导广大青年教师不断提高自己的业 务水平和教学能力, 保持良好的教学状态, 提高课堂 教学质量, 为学院的教育教学质量水平把关, 同时青 年教师的培养和引导也是学院师资队伍建设的一个 重要组成部分, 对进一步提高全体教师的教学水平也 有重要意义。

\section{致谢}

感谢浙江省高等教育十三五第二批教学改革研究 项目 “应用型本科院校教学督导工作实践与策略探 究”，项目编号：JG20190675

\section{REFERENCES}

[1] Geng hui, Construction and improvement of teaching supervision system and working mechanism in Colleges and Universities, Journal of Higher Education Research, V01. 39, No.3, Sep. 2016, pp. 45-48,94.DOI: http://oss.wanfangdata.com.cn/

[2] Zhang hui, Research on the internal monitoring system of teaching quality in private universities, Northwest University, Dec 2014.

[3] Shen jinxiai, The innovation and development of teaching supervision in Colleges and Universities, Chinese university teaching, 2012, (04): pp.71-73, 87. DOI: https://kns.cnki.net/kcms/detail/

[4] Li qunying, Xu xueying, Practice and Reflection on the innovation of teaching supervision in local colleges and Universities, Journal of Hubei Correspondence University, vol.28, NO.12(Gen.NO.154), Jun.(1ast half)2015, pp.27-28,77. DOI: 